\title{
EDITORIAL
}

\section{Artificial Intelligence, Communication and Human Contentment}

\author{
Naren Chitty ${ }^{1}$
}

Content, communication and community are three words that may be examined in relation to the way they are ordered. What are the ontological relationships? Does community precede communication? Must there first be some form of content to communicate? Is it through communication that community arises and content is developed? These are tantalizing questions and ones that are difficult to answer - because we are born into community with content all around us.

Even communication based on grunts and whistles is a tool or technology - an 'extension' of natural capabilities (Hall 1976). Over the millennia technology has become more and more important in our content production, distribution and storage. Machlup (2016) used these three terms in relation to knowledge. And is not content knowledge that is produced, distributed and stored?

Harari (2011, pp. 22 - 44) identifies three communicative abilities that one could say shaped our content, communication and community from the cognitive revolution that occurred 70,000 years ago: His "new communicative abilities were the skills to describe the environment, social relationships and concepts not found in the environment" (Chitty 2017, pg. 13). While these are content production skills, content sharing shapes community. Refinement of communication technology has led progressively to expansion of communities. And now content is being sucked into communication as we see in intelligent networks.

Following the explosive growth in telematics and informatics, we are rapidly approaching a new plateau of social organization where content, community and community will be shaped by Artificial Intelligence (AI). There are short, medium term and long term issues to consider. The long-term issue is the spectre of the singularity. In the medium term there is thepotential for mind emulations entering the workforce. And in the short term we have the opportunity of attempting to generate norms for the issue area of $\mathrm{AI}$, in the construction of an $\mathrm{AI}$ international regime (Krasner 1983).

There is a need for scholarly attention to be devoted to content, communication and community in relation to the rise of $\mathrm{AI}$.

\section{References}

Chitty, N. 2017, "Soft power, civic virtue and world politics". In the Routledge Handbook of Soft Power. (eds) N. Chitty, Li Ji, G. Rawnsley \& C. Hayden. Routledge: London \& New York.

Hall, E 1976, Beyond Culture. Anchor Books

Hanson, R. (2016). The Age of Em: Work, Love and Life when Robots Rule the Earth. Oxford: Oxford University Press

Harari, Y 2011 , Sapiens: a brief history of humankind, Vintage Books , London .

Krasner, S (1983). International regimes, New York: Cornell University Press.

Machlup, F 2016. Knowledge: Its Creation, Distribution and Economic Significance, Volume I Knowledge and Knowledge Production. Princeton University Press. 